\title{
Career pathways and destinations 18 years on among doctors who qualified in the United Kingdom in 1977: postal questionnaire survey
}

\author{
Jean M Davidson, Trevor W Lambert, Michael J Goldacre
}

\begin{abstract}
Objective To determine the career destinations, by 1995, of doctors who qualified in the United Kingdom in 1977; the relation between their destinations and early career choice; and their intentions regarding retirement age.

Design Postal questionnaire.

Setting United Kingdom.

Subjects All $(\mathrm{n}=3135)$ medical qualifiers of 1977 .

Main outcome measures Current employment; year by year trends in the percentage of doctors who worked in the NHS, in other medical posts in the United Kingdom, abroad, in non-medical posts, outside medicine, and in part time work; intentions regarding retirement age.

Results After about 12 years the distribution of respondents by type of employment, and, for women, the percentage of doctors in part time rather than full time medical work, had stabilised. Of all 2997 qualifiers from medical schools in Great Britain, 2399 (80.0\% (95\% confidence interval $79.5 \%$ to $80.6 \%)$ ) were working in medicine in the NHS in Great Britain 18 years after qualifying. Almost half the women $(318 / 656)$ worked in the NHS part time. Of 1714 doctors in the NHS, 1125 intended to work in the NHS until normal retirement age, 392 did not, and 197 were undecided. Of the 1548 doctors for whom we had sufficient information, career destinations at 18 years matched the choices made at 1,3 , and 5 years in 58.9\% (912), 78.2\% (1211), and 86.6\% (1341) of cases respectively.

Conclusions Planning for the medical workforce needs to be supported by information about doctors' career plans, destinations, and whole time equivalent years of work. Postgraduate training needs to take account of doctors' eventual choice of specialty (and the timing of this choice).
\end{abstract}

\section{Introduction}

No large scale prospective national studies in the United Kingdom have followed doctors from qualification to mid-career and beyond. We summarise the career pathways of the cohort of doctors who qualified in the United Kingdom in 1977 up to September 1995, when the great majority of its members were in posts in permanent career grades.

\section{Method}

The methods have been described in detail elsewhere. ${ }^{1}$ The cohort was previously studied 1,3,5, 7, and 9 years after qualifying. ${ }^{2}$ The population used for this survey comprised all medical qualifiers from all medical schools in the United Kingdom in 1977. Each doctor was sent a postal questionnaire together with a covering letter in November 1995, with up to three fol- low up mailings to non-respondents between February and June 1996. We analysed the data taking 30 September 1995 as the standard point in time for our respondents. The questionnaire requested current demographic information, employment details dating back to the time of the most recent information held by us for each doctor, and future career intentions (including any plans for early retirement).

In addition to our own survey data, we had information from the Department of Health's statistical records of doctors in NHS employment on 30 September 1995 in Great Britain-that is, the United Kingdom excluding Northern Ireland. Capturerecapture analysis ${ }^{34}$ was used to estimate the total number of doctors who qualified in 1977 and who were working in the NHS in Great Britain in September 1995. Fourteen specialty groups were defined. We compared respondents' choice of specialty group at 1,3 , and 5 years after qualifying with the specialty group in which they were employed in September 1995. In analysis of part time and full time working, doctors in hospital practice who held "maximum part time" contracts were deemed to be full time. Linear regression was used to analyse time trends in the percentages of respondents in different employment sectors.

\section{Results}

Response rates and employment status

Of the 3135 doctors who qualified in 1977, 21 were known to have died by the time of the survey and 16 did not want to participate; no current address could be found for a further 29. This left 3069 doctors (2068 men). The response rate was $78.1 \%(2398 / 3069)$. As in previous surveys, ${ }^{5}$ a higher percentage of women than men responded $(83.1 \%$ and $75.7 \%$ respectively; $\left.\chi^{2}=21.4, \mathrm{P}<0.001\right)$.

Table 1 summarises the employment status of respondents in September 1995: 97\% of all respondents were in medical practice, either in the United Kingdom or abroad. Overall, more women (29/832 $(3.5 \%))$ than men $(4 / 1566(0.3 \%))$ were not in paid employment $\left(\chi^{2}=41.8, \mathrm{P}<0.001\right)$

Using our survey data and the Department of Health's records, we estimate that the percentage of doctors from the 1977 cohort practising in the NHS in Great Britain on 30 September 1995 (including those in universities with honorary NHS contracts) was $80.0 \%$ (95\% confidence interval $79.5 \%$ to $80.6 \%$; table 2).

\section{Specialties and grades of doctors in medical employment \\ Table 3 presents numbers of doctors within the 14 spe- cialty groups who were in medical employment in the}

UK Medical
Careers Research
Group, Unit of
Health-Care
Epidemiology,
Department of
Public Health,
University of
Oxford, Oxford
OX3 7LF
Jean M Davidson,
research officer
Trevor W Lambert,
statistician
Michael J Goldacre,
director
Correspondence to:
Dr Goldacre
michael.goldacre@
public-health.oxford.
ac.uk
BMJ 1998;317:1425-8 
Table 1 Employment status in September 1995 of respondents who qualified in the United Kingdom in 1977. Values are numbers (percentages)

\begin{tabular}{lccc} 
Employment sector & Men $(\mathbf{n}=\mathbf{1 5 6 6})$ & Women $(\mathbf{n = 8 3 2})$ & Total $(\mathbf{n}=\mathbf{2 3 9 8})$ \\
\hline Respondents in United Kingdom & $1442(92.1)$ & $771(92.7)$ & $2213(92.3)$ \\
\hline In medical employment: & $1418(90.5)$ & $734(88.2)$ & $2152(89.7)$ \\
\hline NHS & $1272(81.2)$ & $675(81.1)$ & $1947(81.2)$ \\
\hline Universities and research & $74(4.7)$ & $23(2.8)$ & $97(4.0)$ \\
\hline Other public sector* & $16(1.0)$ & $16(1.9)$ & $32(1.3)$ \\
\hline Non-public sector & $33(2.1)$ & $19(2.3)$ & $52(2.2)$ \\
\hline Her Majesty's armed forces† & $23(1.5)$ & $1(0.1)$ & $24(1.0)$ \\
\hline Other: & $24(1.5)$ & $37(4.4)$ & $61(2.5)$ \\
\hline Non-medical employment & $9(0.6)$ & $4(0.5)$ & $13(0.5)$ \\
\hline Not in paid employment & $4(0.3)$ & $27(3.2)$ & $31(1.3)$ \\
\hline Occupation not given & $11(0.7)$ & $6(0.7)$ & $17(0.7)$ \\
\hline Respondents abroad & $124(7.9)$ & $61(7.3)$ & $185(7.7)$ \\
\hline In medical employment & $123(7.9)$ & $53(6.4)$ & $176(7.3)$ \\
\hline Other: & & & $2(0.1)$ \\
\hline Non-medical employment & 0 & $2(0.2)$ & $2(0.1)$ \\
\hline Not in paid employment & 0 & $4(0.5)$ & $5(0.2)$ \\
\hline Occupation not given & $1(0.1)$ & & \\
\hline
\end{tabular}

*Includes doctors in the civil service, public health laboratory service, and public sector occupational health. tRespondents were regarded as working in the United Kingdom regardless of geographical location.

Table 2 Estimated number of 1977 qualifiers working in NHS in Great Britain in 1995

\begin{tabular}{lcccccc} 
& $\begin{array}{c}\text { Known to } \\
\text { MCRG and } \\
\text { DoH }\end{array}$ & $\begin{array}{c}\text { Known to } \\
\text { MCRG only }\end{array}$ & $\begin{array}{c}\text { Known to } \\
\text { DoH only }\end{array}$ & $\begin{array}{c}\text { Rest } \\
\text { (estimated) }\end{array}$ & $\begin{array}{c}\text { Total } \\
\text { (estimated) }\end{array}$ & $\begin{array}{c}\text { \% working in the } \\
\text { NHS (95\% CI) }\end{array}$ \\
\hline Men & 1181 & 110 & 314 & 29 & 1634 & 80.5 (79.9 to 81.2) \\
\hline Women & 556 & 104 & 85 & 16 & 761 & $78.6(77.7$ to 79.5) \\
\hline Total $^{*}$ & 1737 & 214 & 399 & 49 & 2399 & 80.0 (79.5 to 80.6) \\
\hline
\end{tabular}

MCRG=Medical Careers Research Group; DoH=Department of Health.

Analysis is confined to Great Britain because comparable data were not available for Northern Ireland. There were 2997 qualifiers (2029 men) from medical schools in Great Britain in 1977.

*Estimates for subpopulations in capture-recapture methods may not total the estimates for the overal population. ${ }^{4}$

Table 3 Specialty profile in September 1995 of respondents from 1977 qualifiers who were in medical employment in United Kingdom and abroad. Values are numbers (percentages)

\begin{tabular}{lccccc} 
& \multicolumn{2}{c}{ United Kingdom } & & \multicolumn{2}{c}{ Abroad } \\
\cline { 2 - 3 } \cline { 6 - 6 } Specialty group & Men(n=1418) & Women $(\mathrm{n}=734)$ & & Men(n=123) & Women( $\mathrm{n}=53)$ \\
\hline General practice & $622(43.9)$ & $342(46.6)$ & & $33(27)$ & $20(38)$ \\
\hline Medical specialties & $175(12.3)$ & $70(9.5)$ & & $21(17)$ & $4(8)$ \\
\hline Paediatrics & $27(1.9)$ & $20(2.7)$ & & $5(4)$ & $4(8)$ \\
\hline Accident and emergency & $14(1.0)$ & $4(0.5)$ & & $1(1)$ & 0 \\
\hline Surgical specialties & $192(13.5)$ & $21(2.9)$ & & $22(18)$ & 0 \\
\hline Obstetrics and gynaecology & $33(2.3)$ & $19(2.6)$ & & $2(2)$ & $4(8)$ \\
\hline Anaesthetics & $108(7.6)$ & $43(5.9)$ & & $8(7)$ & $4(8)$ \\
\hline Radiology & $47(3.3)$ & $22(3.0)$ & $3(2)$ & $3(6)$ \\
\hline Clinical oncology & $12(0.8)$ & $6(0.8)$ & & $5(4)$ & $1(2)$ \\
\hline Pathology & $63(4.4)$ & $40(5.4)$ & & $5(4)$ & $3(6)$ \\
\hline Psychiatry & $63(4.4)$ & $58(7.9)$ & $6(5)$ & $2(4)$ \\
\hline Community health & $12(0.8)$ & $50(6.8)$ & & 0 & $2(4)$ \\
\hline Public health medicine & $26(1.8)$ & $23(3.1)$ & & $3(2)$ & 0 \\
\hline Other specialties & $24(1.7)$ & $16(2.2)$ & & $9(7)$ & $6(11)$ \\
\hline
\end{tabular}

United Kingdom or abroad in September 1995. Among respondents working in medicine in the United Kingdom, similar percentages of men and women were working in general practice $\left(\chi^{2}=1.5\right.$, $\mathrm{P}=0.22)$. A significantly higher percentage of men than women were in the surgical specialties, and significantly more women than men were in psychiatry and community health $\left(\mathrm{P}<0.05\right.$ with the $\chi^{2}$ test). Of those working in the NHS in general practice, $97.9 \%$ (592/605) of men and 83.8\% (280/334) of women were principals. Of those in NHS hospital practice,
$96.2 \%(611 / 635)$ of men and $64.5 \%(171 / 265)$ of women were consultants. Overall, $97.0 \%$ of men and $75.3 \%$ of women working as general practitioners or hospital doctors in the NHS in the United Kingdom were of principal or consultant status $\left(\chi^{2}=210.7\right.$, $\mathrm{P}<0.001)$.

Among respondents working abroad, the largest single specialty was general practice. Almost a fifth of men, but no women, were in the surgical specialties; the next most popular area of work was the hospital medical specialties.

\section{Year by year changes}

The figure shows the annual percentages of men and women respondents working in each employment sector. The proportions of men and women working in substantive NHS posts gradually decreased until about eight years after graduation; for men the proportion working in university posts increased during this period. Subsequently, for men, the proportion working in NHS posts increased and the proportion in university posts gradually decreased. For women, the reduction in the percentage working in the NHS during the first eight years after graduation reflects the increase in those who were not in paid employment or who worked in non-medical jobs during their child rearing years. About $3.5 \%$ of women were not in paid employment (or worked in non-medical jobs) in each year from year 10 onwards; almost half of women were in this category for the whole of this period. The number of men in this category was negligible. The proportion of men working in the United Kingdom in medical jobs outside the NHS and universities is higher than that of women because the doctors working in the armed forces are almost all men.

Linear regression showed no significant changes after 12 years in the percentages of doctors working in the NHS and universities, in medicine in the United Kingdom, and outside medicine.

\section{Full time and part time working}

By 12 years after qualification, many of the women who had taken a break to raise a family had resumed their careers (fig 1), but 48.5\% (318/656) of women NHS doctors were working part time $(41.9 \%(106 / 253)$ of women hospital doctors, $51.2 \%$ (168/328) of women general practitioners). In 1995 (18 years after qualification), the corresponding percentages for doctors working part time were almost unchanged $(48.4 \%, 42.8 \%$, and $52.3 \%$ respectively). However, only $21.8 \%$ (37/170) of hospital consultant posts held by women were part time, compared with $43.7 \%$ (122/279) of general practitioner principal posts. Eleven out of 12 associate specialists and 32 out of 33 clinical assistants were working part time. The percentage of men in the NHS working part time was very small: $5 \%$ of those in general practice and $3 \%$ of those in hospital practice in 1995. The average number of hours worked per week quoted by women working part time in the NHS was 20 hours (17.7 hours for hospital practice and 20.5 hours for general practice). At this time, $92.7 \%$ of women hospital doctors who were working part time and $96.3 \%$ of women general practitioners who were doing so had children, compared with $59.2 \%$ of full time women hospital doctors and $76.5 \%$ of full time women general practitioners. 


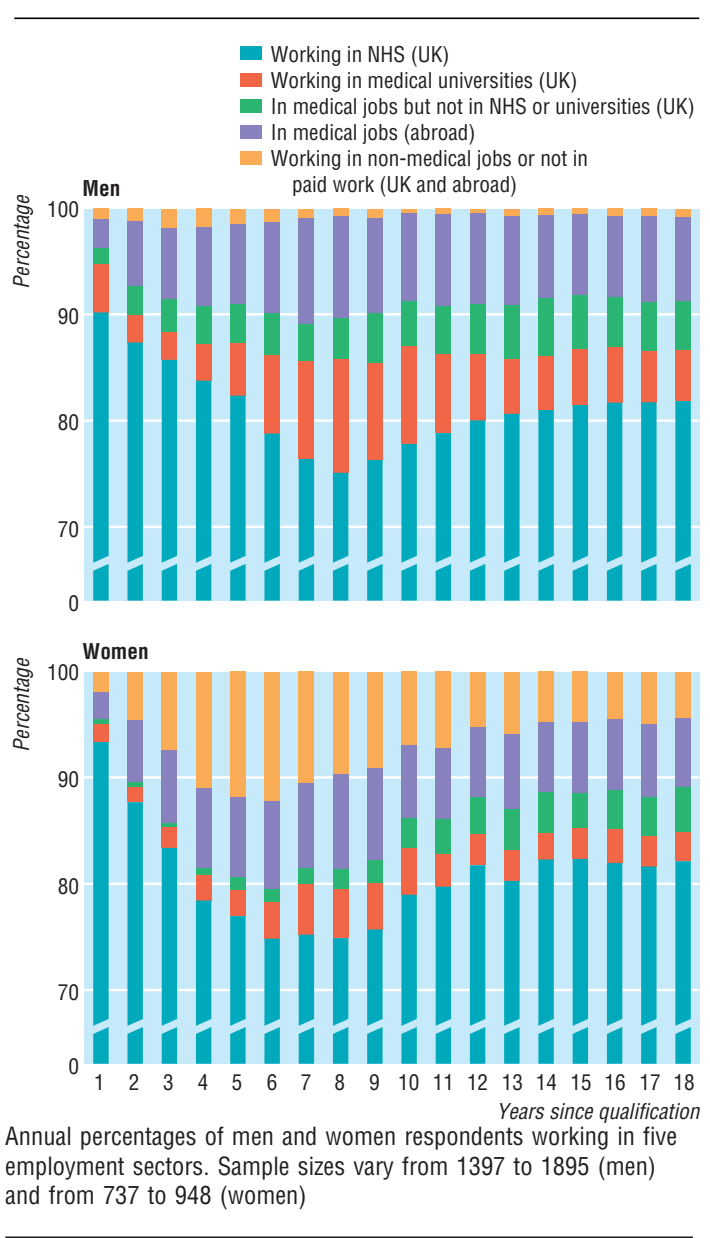

Marital status and adult dependants

Of 1947 respondents working in the NHS in the United Kingdom in 1995 (table 1), 1810 told us their marital status: $91.7 \%$ (1659) were living with a spouse or partner (men 95.1\%, women 85.3\%, $\chi^{2}=53.1$, $\mathrm{P}<0.001)$.

Of the 1745 NHS doctors who answered the question, "are there any dependent adults (for example, disabled, sick, or elderly) in your household whose needs could affect your ability to pursue your chosen career?" 2.7\% (47/1745) answered "yes" (men 2.0\%, women $\left.3.9 \%, \chi^{2}=5.4, \mathrm{P}=0.02\right)$.

\section{Current employment and early career intentions} Overall, 2367/2398 respondents had replied to at least one previous survey. Of these, 1548 doctors (1047 men) currently in medical employment had previously supplied career choices at 1,3 , and 5 years after qualification. We compared their choices in each of these years with their current employment (table 4). As with the 1983 qualifiers, ${ }^{6}$ the relation between early career choice and eventual destination varied considerably between the specialties. The high level of concordance of early choices and eventual destination is particularly striking for surgery. Of the 193 doctors working in the hospital medical specialties in 1995 (table 4), 49 had expressed a year 5 choice for other careers. Most of these had specified general practice as their long term choice in year 5 .

We calculated values for men and women separately for the variables in table 4 . In general prac- tice we found no significant differences between men and women in concordance between early choices and eventual career. In hospital practice, significantly fewer women than men had chosen their current mainstream job at each of 1,3 , and 5 years after qualification $(\mathrm{P}<0.001$ in each case)

\section{Factors influencing career choice}

As in previous studies, ${ }^{5}$ respondents were asked to indicate which of a range of specified factors had influenced their choice of career a great deal, a little, or not at all. In all, 2171 respondents (1403 men, 768 women) provided information about at least one factor. The factors that were scored as having the greatest influence by both men and women were appraisal of their own skills and aptitudes $(70.2 \%(985 / 1403)$ of men and $67.9 \%(521 / 768)$ of women) and enthusiasm for or commitment to the specialty $(62.3 \%$ (874) and $62.2 \%$ (478) respectively). Other factors considered by women to have influenced choice of career a great deal were domestic circumstances $(56.3 \%$ (432) of women $v$ $32.1 \%$ (451) of men respectively; $\chi^{2}=119.5, \mathrm{P}<0.001$ ) and hours and working conditions $(56.3 \%$ (432) $v$ $33.5 \%$ (470) respectively; $\chi^{2}=105.8, \mathrm{P}<0.001$ ). Experience of jobs in training was the next highest influential factor: $47.5 \%$ (666) of men and 42.2\% (324) of women said that it influenced their choice a great deal.

\section{Intention to work until normal retirement age}

Altogether, 1714/1947 of doctors who worked in the NHS answered our question, "do you intend to practise in the NHS until normal retirement age?" In all, 22.9\% (392) of these respondents answered "no" (table 5). Proportionately more women than men in hospital practice definitely or probably intended to continue working in the NHS until normal retirement age ( $70.6 \%$ of women, $61.7 \%$ of men; $\left.\chi^{2}=5.4, \mathrm{P}=0.02\right)$. In general practice there was no significant difference between women and men $(63.5 \%$ v $68.9 \%$ respectively; $\left.\chi^{2}=2.3, \mathrm{P}=0.11\right)$.

Table 4 Percentages (numbers) of 1977 qualifiers in each specialty 18 years after qualification who gave that specialty as their first choice of career at 1,3 , and 5 years after qualification

\begin{tabular}{lccccr} 
Current career specialty & $\begin{array}{c}\text { Chose in } \\
\text { year } \mathbf{1}\end{array}$ & $\begin{array}{c}\text { Chose in } \\
\text { year } \mathbf{3}\end{array}$ & $\begin{array}{c}\text { Chose in } \\
\text { year } \mathbf{5}\end{array}$ & $\begin{array}{c}\text { Did not choose in } \\
\text { any of these years }\end{array}$ & $\begin{array}{c}\text { Total } \\
\text { No }\end{array}$ \\
\hline Hospital practice: & & & & & \\
\hline Medical specialties & $64(124)$ & $69(133)$ & $75(144)$ & $18(35)$ & 193 \\
\hline Paediatrics & $63(25)$ & $85(34)$ & $90(36)$ & $5(2)$ & 40 \\
\hline Accident and emergency & $0(0)$ & $0(0)$ & $50(5)$ & $50(5)$ & 10 \\
\hline Surgical specialties & $84(137)$ & $94(154)$ & $96(157)$ & $2(3)$ & 164 \\
\hline Obstetrics and gynaecology & $62(24)$ & $80(31)$ & $92(36)$ & $5(2)$ & 39 \\
\hline Anaesthetics & $50(59)$ & $85(100)$ & $90(106)$ & $6(7)$ & 118 \\
\hline Radiology & $18(11)$ & $60(37)$ & $86(53)$ & $13(8)$ & 62 \\
\hline Clinical oncology & $28(5)$ & $61(11)$ & $83(15)$ & $17(3)$ & 18 \\
\hline Pathology & $51(40)$ & $72(56)$ & $85(66)$ & $13(10)$ & 78 \\
\hline Psychiatry & $46(45)$ & $63(62)$ & $81(80)$ & $15(15)$ & 99 \\
\hline General practice & $61(442)$ & $82(593)$ & $88(643)$ & $7(50)$ & 727 \\
\hline Total & $58.9(912)$ & $78.2(1211)$ & $86.6(1341)$ & $9.0(140)$ & 1548 \\
\hline
\end{tabular}

For each specialty, the total used in calculating percentages was the number of respondents working in that specialty in September 1995 who gave information on choices in all three years.

Where doctors had designated, as first choices of equal importance, specialties from more than one group, we regarded their current employment as matching their previous first choice if it matched any of these. Choices for community health and public health medicine were not separately identified in early surveys (these specialties are omitted from the table). 
Table 5 Intention to work in the NHS until normal retirement age of 1977 qualifiers working in the NHS in 1995. Values are percentages (numbers) of doctors

\begin{tabular}{llccc} 
& \multicolumn{1}{c}{ Yes $^{*}$} & Undecided & No† & Total No \\
\hline Hospital doctors: & $64.3(507)$ & $9.5(75)$ & $26.1(206)$ & 788 \\
\hline Men & $61.7(341)$ & $9.6(53)$ & $28.8(159)$ & 553 \\
\hline Women & $70.6(166)$ & $9.4(22)$ & $20.0(47)$ & 235 \\
\hline General practitioners: & $67.0(556)$ & $13.0(108)$ & $20.0(166)$ & 830 \\
\hline Men & $68.9(368)$ & $10.3(55)$ & $20.8(111)$ & 534 \\
\hline Women & $63.5(188)$ & $17.9(53)$ & $18.6(55)$ & 296 \\
\hline Totalł: & $65.6(1125)$ & $11.5(197)$ & $22.9(392)$ & 1714 \\
\hline Men & $64.7(721)$ & $10.1(113)$ & $25.2(281)$ & 1115 \\
\hline Women & $67.5(404)$ & $14.0(84)$ & $18.5(111)$ & 599 \\
\hline
\end{tabular}

*Includes those who answered, "yes, definitely" or "yes, probably."

tIncludes those who answered "no, definitely not" or "no, probably not."

fIncludes those working in community health (57 doctors) and public health medicine (39).

\section{Discussion}

This survey was undertaken about 10 years after the previous study of this group of doctors. They are now in their mid-40s, and the great majority are in career positions. Those in senior hospital posts are involved in implementing the Calman changes to postgraduate medical training. ${ }^{7}$ Those in general practice have worked through major changes to general practitioners' contracts and have worked through fundholding.

The reforms to specialist training in the United Kingdom will promote shorter periods of specialist training and may be advantageous to doctors who make definite career choices early. This survey shows that most of the 1977 qualifiers made their choice of eventual career fairly soon after qualification, but a noteworthy minority did not. More women than men were influenced in their choice of career by factors relating to home and lifestyle.

The percentages of doctors working in different employment sectors became stable in this cohort about 12 years after qualifying. The main trends up to this time were, for men, a shift into university employment in the early years followed by a return to substantive NHS employment; and for women, an increase in those not in paid employment followed by a return to medicine.

We estimated that participation in the NHS among these doctors in 1995, including those with honorary NHS contracts, was $80 \%$ (table 2), with little difference between men and women. However, almost $50 \%$ of women had settled into a pattern of part time working by 12 years after qualification. This had not changed subsequently. The self reported hours worked by women in part time jobs averaged 20 hours a week. Assuming this is about half of the whole time equivalent and given that $33 \%$ of the cohort were women, the loss of the whole time equivalent workforce attributable to women's part time work was about $8 \%$. The attributable loss from this cohort is smaller than it will be in more recent cohorts, in which the proportion of women in medicine is much higher.

We asked the doctors currently in the NHS about their intention to remain in the NHS until normal retirement age. The phrase "normal retirement age" may be interpreted differently in different sectors of the NHS, and differently by men and women in the light of recent European directives. Nevertheless, the results show that almost a quarter of these doctors expressed an intention to retire before they are required to do so. An investigation of intentions to retire early, doctors' plans to support early retirement,
- A large scale national study in the United Kingdom followed doctors from qualification to mid-career and beyond

- Most doctors had made their choice of eventual career-at least in terms of broadly defined specialty-within 5 years of qualifying

- Eighteen years on, $80 \%$ of the doctors were working in the NHS and nearly half of women doctors were working part time

- Almost a quarter of NHS doctors planned to retire early

reasons for wanting early retirement, and factors that would influence doctors to stay, would be valuable.

We thank Carol Edwards for her work during the early stages of this study, Janet Justice and Alison Stockford for their careful data entry, Karen Hollick for her administration of the survey, and all the doctors who have participated in the study. James Parkhouse directed the earlier surveys of this cohort.

Contributors: TWL and MJG contributed to the design of the survey. TWL coordinated the survey and provided statistical advice. JMD analysed the data and wrote the first draft. All the authors contributed to further drafts, and all act as guarantors for the paper.

Funding: The UK Medical Careers Research Group is funded by the Department of Health. The Unit of Health Care Epidemiology is funded by the Anglia and Oxford Regional Office of the NHS Executive.

Competing interests: None declared.

1 Parkhouse J. Doctors' careers: aims and experiences of medical graduates. London: Routledge, 1991.

2 Parkhouse J, Ellin DJ. Reasons for doctors' career choice and change of choice. BMJ 1988;296:1651-3.

3 Hook EB, Regal RR. The value of capture-recapture methods even for apparent exhaustive surveys. Am J Epidemiol 1992;135:1060-7.

4 Lambert TW, Goldacre MJ. Career destinations seven years on among doctors who qualified in the United Kingdom in 1988: postal questionnaire survey. BMJ 1998:317:1429-31.

5 Lambert TW, Goldacre MJ, Parkhouse J, Edwards C. Career destinations in 1994 of United Kingdom medical graduates of 1983: results of a questionnaire survey. BMJ 1996;312:893-7.

6 Edwards C, Lambert TW, Goldacre MJ, Parkhouse J. Early medical career choices and eventual careers. Medical Education 1997;31:237-42.

7 Department of Health. Hospital doctors: training for the future. London: HMSO, 1993.

(Accepted 28 July 1998)

\section{Endpiece}

\section{How to avoid contagious diseases}

Take care not to be kidnapped by Sardinian shepherds or by terrorists: the kidnappers as a rule use the same hood for many kidnapped victims. Never travel by train between Florence and Bologna, as terrorist explosions in the confined areas of the tunnels spread organic detritus very quickly, and in such moments of confusion it is difficult to protect oneself. Avoid areas subject to bombardment by nuclear warheads: faced with the sight of a mushroom cloud, the spectator has an instinctive tendency to put his (unwashed) hands to his mouth, as he murmurs, "My God"!

Umberto Eco, How to Travel with a Salmom and Other Essays (1994)

Submitted by Jeff Aronson, honorary consultant physician, Oxford 